\title{
Low-temperature synthesis of zeolite from perlite waste - Part II: characteristics of the products
}

\author{
Magdalena Król*, Justyna Morawska, WŁodzimierz Mozgawa, Waldemar Pichór \\ Faculty of Materials Science and Ceramic, AGH University of Science and Technology, \\ 30 Mickiewicza Av., 30-059 Krakow, Poland
}

\begin{abstract}
The paper investigates the properties of sodium zeolites synthesized using the hydrothermal method under autogenous pressure at low temperature with $\mathrm{NaOH}$ solutions of varying concentrations. During this modification, zeolites $\mathrm{X}, \mathrm{Na}-\mathrm{P}_{1}$ and hydroxysodalite were synthesized. The synthesis parameters, and thus, phase composition of resulting samples, significantly affected the specific surface area (SSA) and cation exchange capacity (CEC). SSA increased from $2.9 \mathrm{~m}^{2} / \mathrm{g}$ to a maximum of $501.2 \mathrm{~m}^{2} / \mathrm{g}$, while CEC rose from $16 \mathrm{meq} / 100 \mathrm{~g}$ to a maximum of $500 \mathrm{meq} / 100 \mathrm{~g}$. The best properties for use as a sorbent were obtained for perlite waste modified with $4.0 \mathrm{M} \mathrm{NaOH}$ at $70{ }^{\circ} \mathrm{C}$ or $80{ }^{\circ} \mathrm{C}$.
\end{abstract}

Keywords: synthesis of zeolites; expanded perlite waste; cation exchange capacity (CEC); specific surface area

(C) Wroclaw University of Technology.

\section{Introduction}

Zeolites are aluminosilicate minerals with interesting, varying physical and chemical properties, due to which they have numerous applications. Some of the properties that we look for in different materials are: high cation exchange capacity or chemical and thermal stability [1]. Most zeolites used commercially are produced synthetically. Inter alia, they can be obtained by heating aluminosilicate raw materials in the presence of alkaline solutions [2].

Results of some studies [3, 4] indicate a tenfold greater cation exchange capacity of synthetic zeolites with respect to the natural ones (e.g. clinoptilolite). Zeolityzation of aluminosilicate materials is a low cost method for the preparation of sorbents, which can be used in wastewater treatment processes. Sodium zeolites obtained in the synthesis from natural or expanded perlite can be successfully used in the sorption processes, in particular for heavy metals [4-8] as well as cyanide ions [9].

In this paper, the results of an experimental study on the formation of zeolites from expanded

*E-mail: mkrol@agh.edu.pl perlite waste in alkaline solutions of various concentrations at different reaction temperatures were reported. The aim of this study was to obtain suitable absorbent material for environmental applications, assuming the time and energy savings. The specific aims were to analyze the resulting zeolitic products in terms of microstructure and functional parameters, such as specific surface area, cation exchange capacity (CEC) and thermal stability.

\section{Experimental}

The perlite waste used in the zeolitization experiments has been produced during separation of expanded perlite products from air classification. This is a light coloured material with the grains size below $0.4 \mathrm{~mm}$. The results of quantification of the starting material normalized to $100 \%$ were as follows (in wt. \%): $\mathrm{SiO}_{2}-75.39 \%, \mathrm{Al}_{2} \mathrm{O}_{3}-$ $13.36 \%, \mathrm{Na}_{2} \mathrm{O}-4.61 \%, \mathrm{~K}_{2} \mathrm{O}-4.11 \%, \mathrm{Fe}_{2} \mathrm{O}_{3}$ $-1.22 \%, \mathrm{CaO}-0.97 \%, \mathrm{MgO}-0.11 \%$, and others $-0.23 \%$. The compositions consist of amorphous aluminosilicate phase and $\mathrm{SiO}_{2} / \mathrm{Al}_{2} \mathrm{O}_{3}$ molar ratio is equal to 9.57 . The synthesis was carried out by mixing the perlite with aqueous solution of sodium hydroxide (alternatively potassium or lithium hydroxide) in the concentration range 
of 3.0 to $5.0 \mathrm{~mol} / \mathrm{dm}^{3}$. The solid-to-solution ratio was maintained at $1: 15(\mathrm{~g} / \mathrm{ml})$ and reaction time was $24 \mathrm{~h}$. The reactions were performed under atmospheric pressure. Different temperatures in the range of 70 of $90{ }^{\circ} \mathrm{C}$ were used. The final solid products were recovered by filtration and washing with distilled water until the $\mathrm{pH}$ of the filtrate was below 10. The samples were dried at temperature not exceeding $80^{\circ} \mathrm{C}$. The alteration products were identified by means of Philips X-ray powder diffraction $\mathrm{X}^{\prime}$ Pert system $\left(\mathrm{CuK}_{\alpha}\right.$ radiation). In order to determine the quantitative composition with an estimate of amorphous phase content, $30 \%$ of corundum as internal standard has been introduced into selected samples. The chemical compositions of perlite waste and resulting samples were determined by the wavelength dispersive $\mathrm{X}$-ray fluorescence spectrophotometer (XRF), Model Axios mAX 4 kW, PANalytical.

Morphology and crystal size were studied by scanning electron microscope FEI Nova NanoSEM 200 (samples were sputtered with graphite).

The porous texture analysis of the resulting products was performed by nitrogen adsorption measurements on Micromeritics ASAP 2010 volumetric adsorption analyzer. The measurements were carried out at a liquid nitrogen temperature $(77 \mathrm{~K})$ in a relative pressure range from about $10^{-6}$ to 1.0. Before measurements the samples were outgassed for about $20 \mathrm{~h}$ at the temperature of $105^{\circ} \mathrm{C}$.

The water contents were obtained by heating $10 \mathrm{mg}$ samples in platinum crucibles at a rate of $10{ }^{\circ} \mathrm{C} / \mathrm{min}$ in air using a thermal analyzer NETZSCH STA 449 F3.

The procedure - ammonium acetate saturation method, recommended by Synthesis Commission of the International Zeolite Association [10] - was employed to determine cation exchange capacity (CEC) of the zeolitic material. Samples of $0.1 \mathrm{~g}$ were shaken with $1 \mathrm{M} \mathrm{NH}_{4} \mathrm{OAc}$, left overnight, and then the eluents were separated by centrifuging; this procedure was repeated 4 times. The number of $\mathrm{NH}_{4}^{+}$ions retained by the zeolite is a measure of the CEC.

\section{Results and discussion}

XRD-patterns of analyzed samples are shown in the Fig. 1. Depending on temperature and $\mathrm{NaOH}$ concentration, identified phases are mainly zeolite $\mathrm{Na}-\mathrm{P}_{1}$, zeolite $\mathrm{X}$ and hydroxysodalite. The crystalline phases content, evaluated based on Rietveld analysis, is in the range of 58 to $80 \%$. The highest yield of zeolite $\mathrm{X}$ was obtained by the synthesis of $4.0 \mathrm{M} \mathrm{NaOH}$ at $70{ }^{\circ} \mathrm{C}$. The formation of almost pure zeolite $\mathrm{Na}-\mathrm{P}_{1}$ was achieved with $3.0 \mathrm{M}$ $\mathrm{NaOH}$ at $90{ }^{\circ} \mathrm{C}$. When the reaction was carried out with the participation of $5.0 \mathrm{M} \mathrm{NaOH}$ and at $90{ }^{\circ} \mathrm{C}$, perlite was converted into a single phase of sodalite. This synthetic zeolite $\mathrm{X}$, zeolite $\mathrm{Na}-\mathrm{P}_{1}$ and hydroxysodalite were used as a standard for further analysis.

In order to examine the morphology of the resulting zeolites, the samples, whose XRD patterns were dominated by one type of zeolite, were inspected by means of a scanning electron microscope. SEM images of these samples are shown in Fig. 2. The microstructure of the starting material is also shown for comparison (Fig. 2a); this sample appeared amorphous, characterized by the honeycomb structure. Microstructure of synthesized zeolite $X$ is shown in Fig. 2b. Zeolite $X$ crystallizes in a form of agglomerates with a large surface development compared to the other samples (Fig. 2c, 2d), what undoubtedly has a positive impact on the sorption capacity of so obtained material. However, residues of perlite grains can be observed. At higher temperature of synthesis, an increase in crystallinity and grain size is observed. Zeolite Na- $\mathrm{P}_{1}$ forms aggregates of almost spherical shapes (Fig. 2c). Crystallites of sodalite, visible in Fig. 2d, are characterized by lamellar growth habit of larger size. These observations suggest that higher crystallization temperature and higher $\mathrm{pH}$ of synthesis solution is appropriate for the synthesis of crystalline materials.

Actual density of the sample obtained at $50{ }^{\circ} \mathrm{C}$ is close to the density of the starting material $\left(2.26 \mathrm{~g} / \mathrm{cm}^{3}\right)$. Based on XRD analysis, no presence of crystalline phases has been detected at this temperature. Some differences in density can be observed in the samples obtained at $60{ }^{\circ} \mathrm{C}$, which is 
(a)

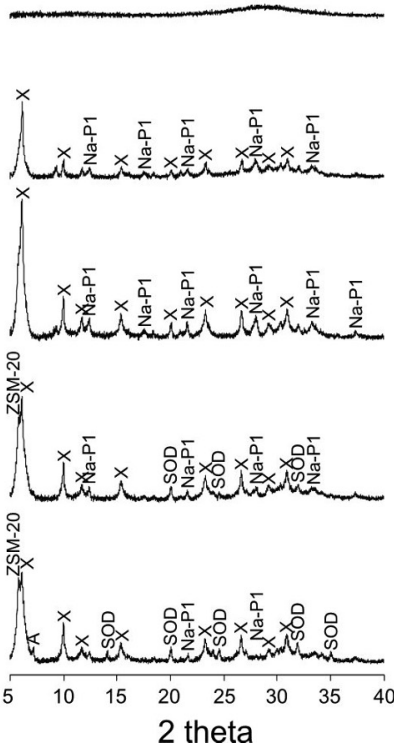

(b)
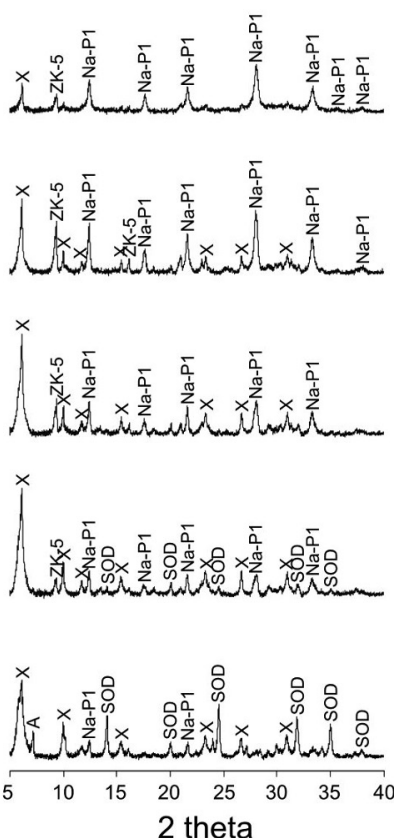

(c)
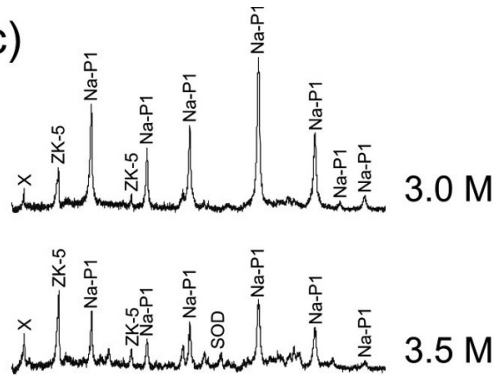

$3.5 \mathrm{M}$
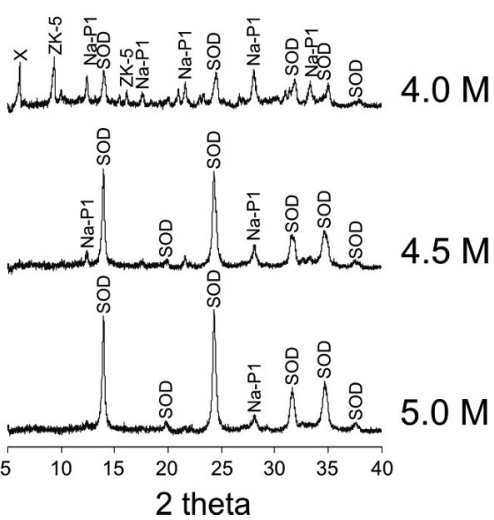

Fig. 1. XRD patterns of the samples obtained at 70 (a), 80 (b), and $90{ }^{\circ} \mathrm{C}$ (c) after $24 \mathrm{~h}$, at various $\mathrm{NaOH}$ concentration.
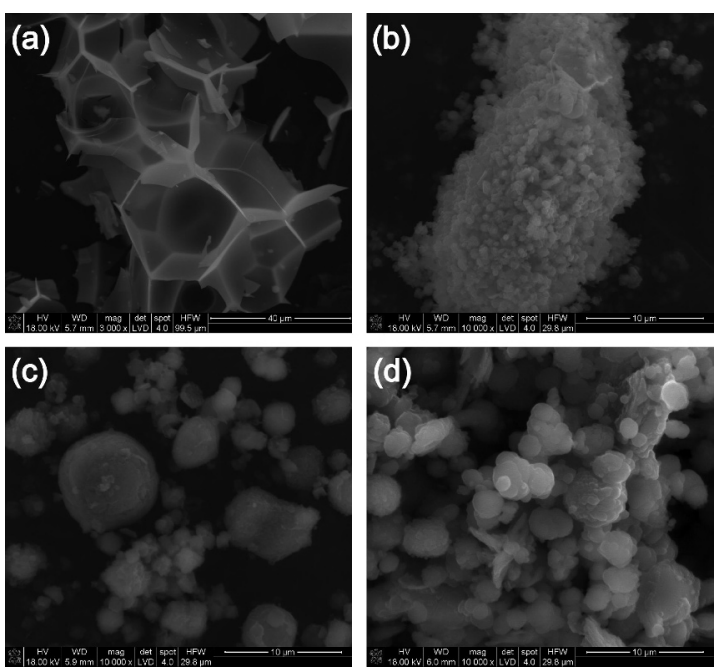

Fig. 2. SEM observations of the initial perlite (a) and the samples obtained from $4.0 \mathrm{M} \mathrm{NaOH}$ at $70{ }^{\circ} \mathrm{C}$ (b), 3.0 M NaOH at $90^{\circ} \mathrm{C}$ (c), and 5.0 $\mathrm{M} \mathrm{NaOH}$ at $90{ }^{\circ} \mathrm{C}(\mathrm{d})$.

associated with the appearance of zeolite X. The greatest amount of this phase correlates with the lowest density of the resulting material, which is equal to $2.03 \mathrm{~g} / \mathrm{cm}^{3}$. The samples with the highest actual density contain sodalite in their phase composition.

The specific surface areas of the samples were determined both by BET and Langmuir equation in the region of relative pressure of 0.06 to 2.00 of the adsorption isotherms. All derived data are listed in Table 1. Most zeolites have type I adsorption isotherms in a Brunauer classification [11], which are characteristic of monolayer adsorption, therefore some researchers consider the Langmuir equation for a more appropriate. However, keeping in mind that the samples have a multiphase structure, both results are presented. The value of surface area of zeolites, reported in the related literature, is in the range of 500 to $800 \mathrm{~m}^{2} / \mathrm{g}$ [12]. The values of total surface area, calculated here using Langmuir's method, are slightly lower. This is due to the presence of a certain amount of glassy phase in the sample. Fig. 3 illustrates the variation in specific surface area with temperature of the synthesis. The hydrothermal treatment of perlite waste with alkaline solution clearly increases the surface area 
of this material. This is most visible in the case of sample treated at $50{ }^{\circ} \mathrm{C}$, whose surface area was measured to be $17.05 \mathrm{~m}^{2} / \mathrm{g}$. This is significantly higher than the surface area of the raw material $\left(4.06 \mathrm{~m}^{2} / \mathrm{g}\right)$. Further rapid increase in the surface area to $501.21 \mathrm{~m}^{2} / \mathrm{g}$ may be due to both degradation of perlite structure and formation of zeolite $\mathrm{X}$. This zeolitic phase is characterized by the largest volume of cavities among the analyzed structures [2], which results in a high surface area of micropores. Further temperature increase caused a decrease in the surface area again. This observation can be ascribed to the formation of zeolite $\mathrm{Na}-\mathrm{P}_{1}$ and next to the conversion of zeolite $\mathrm{Na}-\mathrm{P}_{1}$ to hydroxysodalite. The decrease in surface area reflects the crystallization of increasingly compact structures. These observations agree well with the results of SEM observations (Fig. 2). Similarly, the specific surface area of resulting samples depends on the $\mathrm{NaOH}$ concentration (Table 1). At $90{ }^{\circ} \mathrm{C}$ this parameter is higher for the sample obtained by treating with $4.0 \mathrm{M} \mathrm{NaOH}$ solution $\left(60.56 \mathrm{~m}^{2} / \mathrm{g}\right)$. This probably corresponds with the presence of some amount of zeolite X. Hydroxysodalite is formed at the higher analyzed $\mathrm{NaOH}$ concentration.

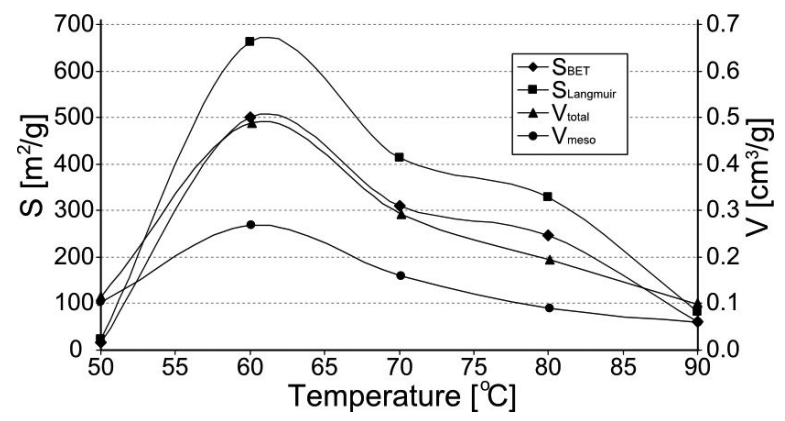

Fig. 3. Specific surface areas (S) and pore volumes (V) of zeolitic materials obtained by the treatment with $4.0 \mathrm{M} \mathrm{NaOH}$ at various temperatures of the synthesis.

The distribution of the pore structures in the resulting materials, determined on the basis of the BJH equation (Fig. 4), is dominated by pores with a diameter of 50 to $200 \mathrm{~nm}$, which is related to the presence of structural defects as well as intercrystalline pores. The high pore volume must have a positive influence on the diffusion processes. The trend of changes in the mesopore volume with the temperature cannot be observed (Table 1), but the mesopore volume increases with increasing $\mathrm{NaOH}$ concentration. The peaks less than $10 \mathrm{~nm}$ (Fig. 4) are probably due to the presence of zeolite structures. However, they cannot be analyzed because the used nitrogen absorption method is not applicable in the study of micropores in this type of structures [13].

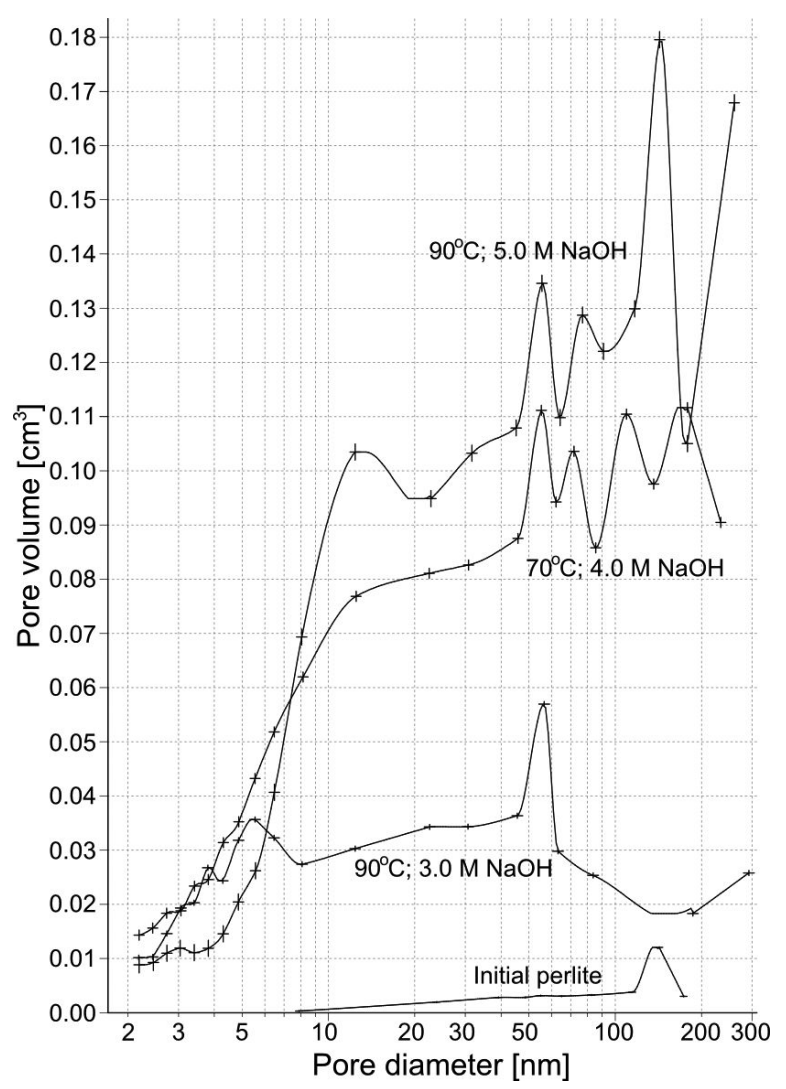

Fig. 4. Pore size distributions for selected samples calculated using the BJH method.

The possibility of using zeolitic materials as sorbents of heavy metal cations is determined mainly by cation exchange capacity (CEC). CECs of zeolitic materials obtained in the process are listed in Table 2. The analysis of obtained data indicates that the perlite waste is activated with respect to cation exchange capacity during the synthesis process. $\mathrm{NH}_{4}^{+}$exchange capacity of zeolitic materials obtained in the process ranges from 402 to $504 \mathrm{meq} / 100 \mathrm{~g}$. This parameter is dozens of times higher than CEC of perlite waste used as the 
Table 1. Textural and thermal properties of initial perlite and selected samples obtained at different conditions.

\begin{tabular}{|c|c|c|c|c|c|c|c|}
\hline \multirow{2}{*}{\multicolumn{2}{|c|}{$\begin{array}{c}\text { Sample } \\
\text { Temp. }\left[{ }^{\circ} \mathrm{C}\right] \mathrm{C}_{\mathrm{NaOH}}\left[\mathrm{mol} / \mathrm{dm}^{3}\right]\end{array}$}} & \multirow{2}{*}{$\begin{array}{c}\text { Actual density } \\
{\left[\mathrm{g} / \mathrm{cm}^{3}\right]} \\
\end{array}$} & \multicolumn{2}{|c|}{ Surface area $\left[\mathrm{m}^{2} / \mathrm{g}\right]$} & \multicolumn{2}{|c|}{ Pore volume $\left[\mathrm{cm}^{3} / \mathrm{g}\right]$} & \multirow{2}{*}{$\begin{array}{c}\text { Thermal stability } \\
{\left[{ }^{\circ} \mathbf{C}\right]} \\
\end{array}$} \\
\hline & & & $\mathrm{S}_{\text {BET }}$ & $S_{L}$ & $\mathbf{V}_{\text {total }}$ & $\mathbf{V}_{\text {meso }}$ & \\
\hline- & - & 2.26 & 2.87 & 4.06 & 0.018 & 0.003 & - \\
\hline 50 & 4.0 & 2.27 & 17.05 & 23.47 & 0.117 & 0.105 & - \\
\hline 60 & 4.0 & 2.18 & 501.21 & 664.11 & 0.484 & 0.267 & - \\
\hline 70 & 4.0 & 2.03 & 311.11 & 414.02 & 0.290 & 0.160 & 610 \\
\hline \multirow[t]{2}{*}{80} & 4.0 & 2.06 & 245.93 & 328.14 & 0.193 & 0.091 & 629 \\
\hline & 3.0 & 2.15 & 31.71 & 43.42 & 0.097 & 0.062 & 636 \\
\hline \multirow[t]{2}{*}{90} & 4.0 & 2.11 & 60.56 & 81.71 & 0.202 & 0.186 & 612 \\
\hline & 5.0 & 2.28 & 46.19 & 63.53 & 0.193 & 0.187 & 611 \\
\hline
\end{tabular}

starting material, which is about 16 meq/100g. Also all the obtained values are higher than the capacity of natural zeolites, e.g. clinoptilolite 260 to $280 \mathrm{meq} / 100 \mathrm{~g}$ [14].

CEC values depend significantly on synthesis parameters (Table 2). In the case of samples obtained at $60{ }^{\circ} \mathrm{C}$, CEC increases with the concentration of initial solution, which results from the increase of the quantity of the reaction products. On the other hand, for 70 and $80{ }^{\circ} \mathrm{C}$ the highest values were detected in the samples obtained using 4.0 $\mathrm{M} \mathrm{NaOH}$, which corresponds with a high content of zeolite X. Among resulting phases, this zeolite has both the highest sorption capacity and the volume of voids in the framework [2]. As mentioned, its largest quantities were obtained at $70{ }^{\circ} \mathrm{C}$ using a $4.0 \mathrm{M} \mathrm{NaOH}$ solution. Additionally, the analysis of microstructure of the described sample (Fig. 2b) indicates a high surface development. Higher $\mathrm{NaOH}$ concentration results in the formation of sodalite structure, characterized by worse parameters in terms of sorption processes. Decrease in the CEC value determined at $90{ }^{\circ} \mathrm{C}$ reflects the presence of sodalite (Fig. 5a). A slightly different situation is in the case of materials synthesized at $90{ }^{\circ} \mathrm{C}$ at various $\mathrm{NaOH}$ concentrations (Fig. 5b). Since zeolite Na- $\mathrm{P}_{1}$ is converted into hydroxysodalite, CEC decreases in the range of 3.0 to 4.0 $\mathrm{M} \mathrm{NaOH}$. On the other hand, the high value for the 4.5 and $5.0 \mathrm{M} \mathrm{NaOH}$ modification does not correspond with the observed phase changes. Substitution of water molecules by $\mathrm{NaOH}$ [2] may explain the very high CECs detected for sodalitecontaining zeolites obtained in a highly alkaline environment. This can be confirmed by measuring the infrared spectra (results presented in the first part of this work): vibration bands related to carbonate groups indirectly indicate the presence of sodium hydroxide in the reaction products.

The amount of Si remaining in the solid phase decreases gradually with $\mathrm{NaOH}$ concentration as well as the temperature of synthesis. From the viewpoint of application of the resulting materials, the share/content of aluminum seems to have an important influence on the emergence of a higher number of cation exchange positions. The smaller the $\mathrm{Si} / \mathrm{Al}$ ratio, the greater ion exchange capacity is observed (Fig. 5). On the other hand, the CEC does not follow the pattern observed for the surface area (Fig. 3). It can be concluded that both the chemical and phase compositions of materials are the main factors affecting the value of the CEC.

Thermal methods, such as TG or DTA, have often been used to characterize zeolite material for their thermal stability as well as quantity of zeolitic water by monitoring of weight loss. The thermal behaviors of selected zeolitic materials are presented in Table 1. Thermogram of the exemplary sample is shown in Fig. 6. The highest rate of dehydration was observed in the range of 25 to $120^{\circ} \mathrm{C}$, which is associated with the release of water molecules adsorbed on the surface of zeolite. These particles are not incorporated into the zeolite structure, and therefore the dehydration speed 
Table 2. CECs of initial perlite and obtained zeolitic materials.

\begin{tabular}{|c|c|c|c|c|}
\hline & Sample & & & \\
\hline Temp. $\left[{ }^{\circ}\right.$ & C] $\mathrm{C}_{\mathrm{NaOH}}\left[\mathrm{mol} / \mathrm{dm}^{3}\right]$ & $\mathbf{S I} / \mathrm{A}$ & $N a / S$ & {$[\mathrm{meq} / \mathrm{g}]$} \\
\hline- & - & 4.78 & 0.12 & 16 \\
\hline 60 & 4.0 & 1.24 & 1.37 & 431 \\
\hline & 4.0 & 1.29 & 1.05 & 444 \\
\hline 70 & 4.5 & 1.19 & 1.21 & 429 \\
\hline & 5.0 & 1.08 & 1.30 & 402 \\
\hline & 4.0 & 1.31 & 1.09 & 473 \\
\hline 80 & 4.5 & 1.23 & 1.21 & 448 \\
\hline & 5.0 & 1.15 & 1.41 & 444 \\
\hline & 3.0 & 1.46 & 0.93 & 483 \\
\hline & 3.5 & 1.31 & 1.28 & 452 \\
\hline 90 & 4.0 & 1.18 & 1.57 & 433 \\
\hline & 4.5 & 1.06 & 1.73 & 473 \\
\hline & 5.0 & 1.02 & 1.89 & 504 \\
\hline
\end{tabular}

(defined as weight loss in time) in this range is higher than at higher temperatures. The DTA curve showed the typical for zeolites endothermic effect at about $200{ }^{\circ} \mathrm{C}$, which corresponds to structural water loss in TG data. The trace also showed that the resulting structures were stable to at least $580{ }^{\circ} \mathrm{C}$.

\section{Conclusions}

The synthesized material samples exhibited much greater specific surface areas and cation exchange capacities than the initial perlite byproduct. Zeolite $\mathrm{X}$ is potentially a better sorbent than zeolite Na- $\mathrm{P}_{1}$, and zeolite $\mathrm{Na}-\mathrm{P}_{1}$ is probably more effective in removing cations than hydroxysodalite, but both were much improved when compared to the initial perlite. High potential for application is related to the high CEC values. Despite some potential in ion exchange of perlite waste, the products of their zeolitization provide a much better possibility of ion exchange. The CEC rose from $16 \mathrm{meq} / 100 \mathrm{~g}$ solid to a maximum of 444 and $473 \mathrm{meq} / 100 \mathrm{~g}$ for the samples obtained respectively at $70{ }^{\circ} \mathrm{C}$ and $80{ }^{\circ} \mathrm{C}$ using $4.0 \mathrm{M} \mathrm{NaOH}$. However, it should be noted that the reported values
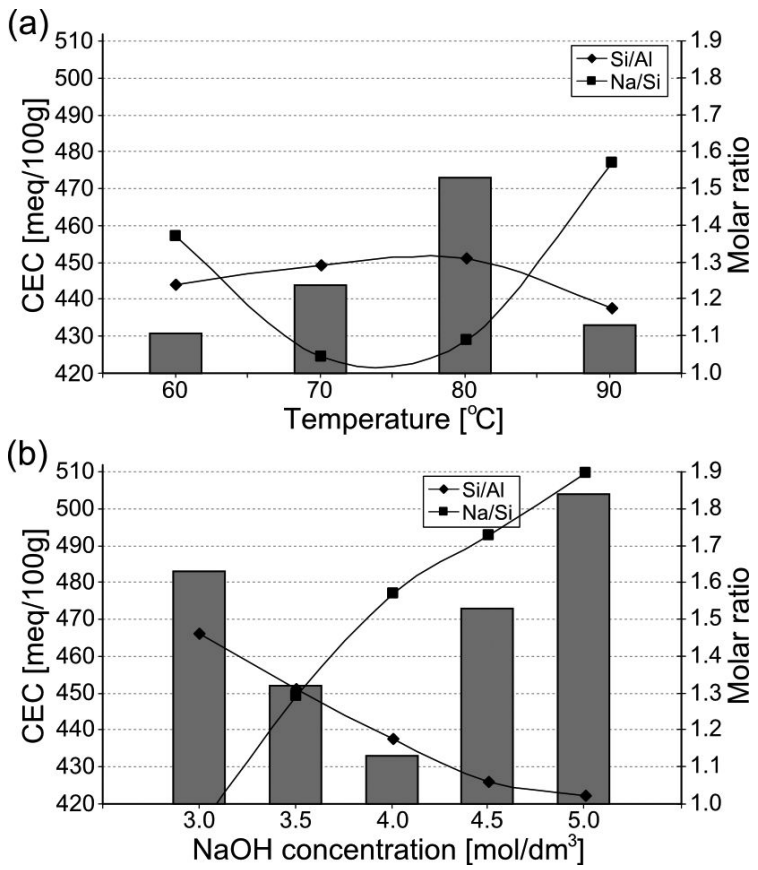

Fig. 5. CEC of resulting materials at various temperatures of synthesis using $4.0 \mathrm{M} \mathrm{NaOH}$ (a), and $\mathrm{NaOH}$ concentration at $90^{\circ} \mathrm{C}(\mathrm{b})$.

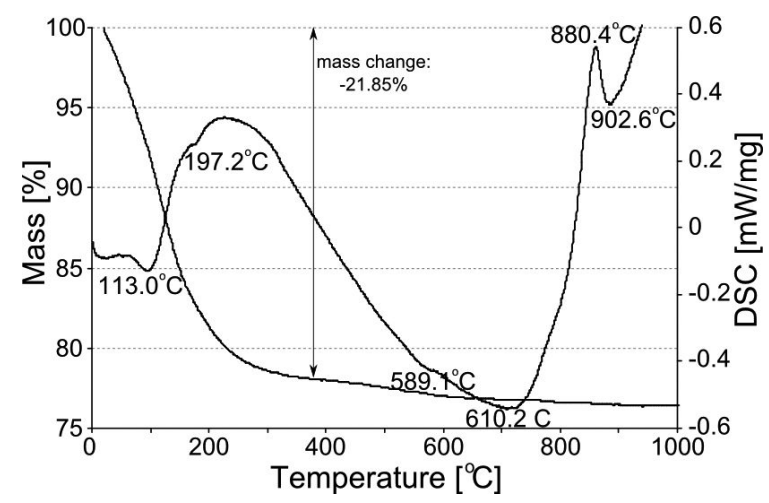

Fig. 6. Thermogram of a sample obtained from $5.0 \mathrm{M}$ $\mathrm{NaOH}$ at $70{ }^{\circ} \mathrm{C}$.

were determined under controlled laboratory conditions. In real applications they may be lower, e.g. since the temperature depend.

In conclusion, it was found that a material with excellent sorption capacity can be produced at low costs using a $4.0 \mathrm{M} \mathrm{NaOH}$ solution at $70{ }^{\circ} \mathrm{C}$ and process duration of $24 \mathrm{~h}$. The specific surface area of the resulting products is even a few dozen times higher and its value achieves a maximum of 
$500 \mathrm{~m}^{2} / \mathrm{g}$. Analyzed materials are stable to temperatures at about $600{ }^{\circ} \mathrm{C}$.

The resulting products show a grater cation exchange capacity than natural materials, such as clay or natural zeolites. It is envisaged that this procedure can convert difficult to store wastes into a beneficial product, which would prove effective in removing heavy metals from contaminated effluent streams. It seems to be useful to conduct studies on the sorption of metals on synthetic zeolites in terms of their wider use.

\section{Acknowledgements}

This work is financial supported by The National Centre for Research and Development (NCBiR) under grant no. PBS1 177206.

\section{References}

[1] Ciciszwili G.W., Andronikaszwili T.G., Kirow G.N., FILIzowa Ł.D., Zeolity naturalne (in Polish), WNT, Warszawa, 1990.

[2] BReCK D.W., Zeolite Molecular Sieves, John Wiley \& Sons, New York - London - Sydney - Toronto, 1974.

[3] Christidis G.E., Papantoni H., Open Miner. J., 2 (2008), 1.

[4] Moirou A., Vaxevanidou A., Christidis G., Paspaliaris I., Clay. Clay Miner., $48 / 5$ (2000), 563.

[5] Dyer A., TANGKaWANit S., RANGSRIWATANANON K., Micropor. Mesopor. Mat., 75 (2004), 273.
[6] TANGKAWAnit S., Synthesis of zeolites from perlite and study of their ion exchange properties, Suranaree University of Technology, 2004.

[7] Christidis G.E., Galani K., Markopoulos T., Synthesis of high added value zeolites from perlite and expanded perlite waste materials, in: ScOTT P.W., BRISTOW C.M. (Eds.), Industrial Minerals and Extractive Industry Geology, The Geological Society Publishing House, UK, 2002, p. 345.

[8] Tangkawanit S., Rangsriwatananon K., Dyer A., Micropor. Mesopor. Mater., 79 (2005), 171.

[9] Faghinian H., Kamali M., Int. J. Environ. Pollut., 19/6 (2003), 557.

[10] DYER A., Ion exchange capacity, [in:] RoBSON H. (Ed.), Verified syntheses of zeolitic materials, Elsavier, 2011, p. 67.

[11] Yates D.J.C., Can. J. Chem., 46 (1968), 1695.

[12] Satterfield C.N., Heterogeneous Catalysis in Practice, McGraw-Hill, New York, 1980.

[13] RuthVen D.M., Charaacterization of zeolites by sorption capacity measurments, [in:] RoBSON H. (Ed.), Verified syntheses of zeolitic materials, Elsevier, 2011, p. 61.

[14] IngleZaKis V.J., HADJIANDREOU K.J., DiAmandis N.A., LoIZIDOU M.D., GRIGOROPOULOU H.P., Water Res., 35 (2001), 2161. 